Title page

\title{
Characteristics and outcomes of Rapid Response Team activations for hypotension in orthopaedic patients
}

\author{
Ramos JGR ${ }^{1}$, Zhang $\mathrm{R}^{2}$, Maher $\mathrm{B}^{3}$, Hardidge $\mathrm{A}^{4}$, Weinberg $\mathrm{L}^{5}$, Robbins $\mathrm{R}^{6}$, Peyton $\mathrm{P}^{7}$, Bellomo $\mathrm{R}^{8}$, \\ Jones $D^{9}$
}

\section{Authors details}

${ }^{1}$ João Gabriel Rosa Ramos, MD, PhD

Intensive Care Unit, Hospital Sao Rafael, Salvador, \& UNIME Medical School, Lauro de Freitas, Brazil

${ }^{2}$ Richard Zhang

Orthopaedic registrar, Department of Orthopaedic Surgery, Austin Health, Heidelberg, Victoria, 3084, Australia

${ }^{3}$ Brendan Maher

Orthopaedic registrar, Department of Orthopaedic Surgery, Austin Health, Heidelberg, Victoria, 3084, Australia

${ }^{4}$ Andrew Hardidge

Director department of Orthopaedic Surgery, Austin Health, Heidelberg, Victoria, 3084,

Australia

${ }^{5}$ Laurence Weinberg

Director, Department of Anaesthesia, Austin Hospital \& A/Prof. Departments of Surgery and Anaesthesia Perioperative Pain Medicine Unit, University of Melbourne.

This is the author manuscript accepted for publication and has undergone full peer review but has not been through the copyediting, typesetting, pagination and proofreading process, which may lead to differences between this version and the Version of Record. Please cite this article as doi: $10.1111 / \mathrm{imj} .14374$

This article is protected by copyright. All rights reserved. 
${ }^{6}$ Ray Robbins

Business Intelligence Unit, Austin Health, Heidelberg, Victoria, 3084, Australia

${ }^{7}$ Phillip J Peyton. Professor, Anaesthesia, Perioperative and Pain Medicine Unit, Melbourne Medical School, University of Melbourne. Associate Professor, Department of Surgery, Austin Health, University of Melbourne. Head of Research, Dept of Anaesthesia, Austin Health

${ }^{8}$ Rinaldo Bellomo

Director of Data Analytics and Evaluation (DARE) Centre, Austin Health, Heidelberg, Victoria, 3084, Australia, and Centre for Integrated Critical Care, The University of Melbourne, Parkville, Victoria, Australia.

${ }^{9}$ Daryl Jones (Corresponding author)

A/Prof School of public health and preventive medicine. Monash University.

Consultant, Intensive Care Unit, Austin Health Studley Road, Heidelberg, Victoria, 3084, Australia. Adjunct A/Prof Department of surgery, University of Melbourne.

Email: Daryl.Jones@austin.org.au

None of the authors have any financial or other competing interests to declare.

DJ and JGRR conceived the study and conducted the data analysis

JGRR, RZ, BM and RR conducted the data extraction

All authors contributed significantly to the drafting and revision of the manuscript

DJ takes responsibility for the integrity of the study

\section{Word count}

Article: 3148

Abstract: 248

This article is protected by copyright. All rights reserved. 


\section{Abstract}

Background: Hypotension following orthopaedic surgery has been associated with increased morbidity and mortality. Rapid Response Teams (RRTs) review patients on hospital wards with hypotension.

Aims: To evaluate the epidemiology of hypotensive RRT activations in adult orthopaedic patients to identify contributing factors, and areas for future quality improvement.

Methods: Retrospective observational study using data from RRT and clinical informatics databases. Evaluation of timing, presumed causes of hypotension and associated treatments.

Results: Amongst 963 RRT activations in 605 patients over three years, 226/605 (37.4\%) of first calls were due to hypotension and $213 / 226(94.2 \%)$ had sufficient data for analysis. The median age was 79 (IQR 66-87) years, 58 (27.2\%) were male, and co-morbidities were common. Most (68\%) surgery was emergent and $75.1 \%$ received intra-operative vasopressors for hypotension. Most activations occurred within 24 hours of surgery, and hypovolemia, infection and arrhythmias were common presumed causes. Fluid boluses occurred in 173 (81.2\%), and the time between surgery and RRT activation was 10 (4.0-26.5) $\mathrm{hr}$ in cases where fluid boluses were given, compared with $33(15.5-61.5) \mathrm{hr}$ where they were not $(p<0.001)$. Blood transfusion $(30,14.1 \%)$ and withholding of medications were also common. Hospital mortality was $8.5 \%(18)$, and $13.6 \%(29)$ were admitted to critical care at some stage. In hospital death was associated with older age, functional dependence, arrhythmia and presumed infection.

Conclusions: Hypotension-related RRT calls in orthopaedic patients are common. Future interventional studies might focus on peri-operative fluid therapy and vaso-active medications, as well as withholding of anti-hypertensive medications pre-operatively.

\section{Keywords}

Orthopedic surgery; Rapid Response System; Rapid Response Team; Medical Emergency Team; Intensive Care Unit; Hypotension

This article is protected by copyright. All rights reserved. 


\section{Introduction}

As the population ages, the number of orthopaedic surgeries performed annually continues to increase(1). Major orthopaedic surgery poses a significant physiological challenge to patients placing them at significant risk of post-operative deterioration. In turn, this is associated with the development several complications (2), in particular cardio-respiratory compromise (2) (3) and unplanned intensive care unit (ICU) admission (4). Several efforts have been made to enhance the identification of orthopaedic patients at risk of postoperative deterioration. One such intervention is the rapid response system (5) (RRS). RRSs are a critical care resource that respond to deteriorating patients within the hospital system, preventing adverse events and improving postoperative outcomes $(6,7)$. Implementation of RRSs has been associated with a reduction of unexpected cardiac arrests (8) and, possibly reduced hospital mortality (9). The responding team of the RRS is referred to as the Rapid Response Team (RRT).

Hypotension has been reported to be a common complication after orthopaedic surgery (10), and poses a significant risk for short-term and long-term morbidity and mortality (11). The differential diagnosis of postoperative hypotension and its subsequence treatment is challenging. A single centre study of 13,656 RRT calls in a heterogenous surgical population revealed that $31 \%$ of calls were due to hypotension. Interestingly, $70 \%$ of such patients received an immediate bolus of fluid administration (12), suggesting pre-emptive fluid administration may prevent RRT calls. The applicability of such findings to patients undergoing

This article is protected by copyright. All rights reserved. 
orthopaedic surgery remains unknown. Hypotension may also result from activation of inflammatory processes due to tissue trauma and bone cement implantation syndrome (13).

Given the dearth of literature in this patient group, we undertook a retrospective observational study to describe the epidemiology of RRT activations for hypotension in orthopaedic patients. The aim of the study was to identify factors that may cause hypotensive RRT calls, to guide potential future interventional studies. Specially, we assessed the timing of RRT activations in relation to surgery and potential factors that may contribute to the call. We also assessed the investigations and treatment delivered during the call, particularly the need for interventions other than fluid administration. We also assessed frequency of pre-operative administration of renin-angiotensin axis inhibitors (potential vaso-dilators) and of intraoperative bone cement implantation. Finally, we assessed patient outcomes at hospital discharge, as well as differences in outcomes of patients who received a fluid bolus and cement fixation, compared with those who did not.

This article is protected by copyright. All rights reserved. 


\section{Methods}

\section{Ethics}

We obtained ethics approval to perform the study (LNR/16/Austin/166). The need for informed written consent from participants was waived due to the observational and retrospective nature of the study.

\section{Setting}

Austin Hospital is a major teaching hospital affiliated with the University of Melbourne and admits approximately 24,000 multi-day admissions each year. Austin Health performs approximately 38,000 surgical procedures annually, including complex cardiothoracic surgery, hepatobiliary-pancreatic surgery, liver transplantation, and major spinal and orthopaedic surgery. The orthopaedic surgical unit provides services to over 15,000 outpatients annually and performs more than 2,500 operations per year.

\section{Description of the Rapid Response System}

The RRS was introduced in 2000 and the RRT is staffed by an intensive care registrar and nurse. The call can be activated by any member of ward staff (medical or nursing) in response to predefined physiological derangements (based on airway difficulty, deranged vital signs, and altered conscious state), as well as a worried criterion. The trigger for activation of a hypotensive RRT call is a systolic blood pressure $(\mathrm{SBP})<90 \mathrm{mmHg}$. An electronic database is maintained that records details of the patients who are reviewed by the RRT in real time. As

This article is protected by copyright. All rights reserved. 
part of this process, the RRT medical team leader documents the presumed cause of the RRT call.

\section{Population and study design}

We retrospectively retrieved all RRT activations in adult orthopaedic patients aged 18 years and over that were recorded between January 2012 to December 2015 and analysed those RRT activations that were due to hypotension ( $\mathrm{SBP}<90 \mathrm{mmHg}$ ). In the case of multiple RRT activations, we only analysed the first event.

\section{Details of data collected}

Data was extracted from the hospital's electronic medical record and the electronic RRT database. We collected data on patient demographics including age and gender, pre-operative anti-hypertensive use, details of co-morbidities and pre-operative vital signs. We also recorded the urgency and type of surgery as well as the use of intra-operative cement fixation. In addition, we documented the nature of anaesthesia used (regional or general), duration of surgery, use of fluids and vasoactive medications (as bolus or infusion), and use of opioid medications.

Events surrounding the RRT activation including the timing of the call in relation to surgery, diurnal variation of the call, the vital signs at the time of RRT activation, the suspected cause for the hypotension as documented by the attending RRT medical team leader, as well as investigations and therapies performed. We also extracted measurements of total plasma cortisol taken around the time of the RRT call.

\section{Statistical analyses}

This article is protected by copyright. All rights reserved. 
Categorical variables were described as counts and proportions. Continuous variables were found to be skewed in distribution and were thus described as median and interquartile range. Proportions were compared with chi-square or Fisher's exact test as appropriate, and continuous variables were compared with Mann-Whitney $\mathrm{U}$ test. We assessed for differences in the characteristics and outcomes of patients who had cement use intra-operatively, as well as differences in the characteristics and outcomes of patients who received a fluid bolus during the RRT call. Finally, we assessed for differences in survivors versus non-survivors following a hypotensive RRT call. A two-sided $p$-value of $p<0.05$ was considered as significant in all analyses. SPSS $21.0^{\mathrm{TM}}$ (SPSS Inc., USA) was used as database and statistical software.

\section{$\underline{\text { Results }}$}

Between 2012 to 2015, there were 963 RRT activations affecting 605 adult orthopaedic patients. Analysis of the first RRT activation revealed that there were 226/605 (37.4\%) were due to hypotension. Amongst these 226 patients, sufficient data was available for 213 (94.2\%) patients. RRT activations varied slightly according to year with 64 (30\%), 48 (22.5\%), 57 (26.8\%) and 44 (20.7\%) activations in 2012, 2013, 2014 and 2015, respectively.

\section{Details of patients with RRT activation for hypotension}

For the 213 patients with first RRT activation due to hypotension, the median (IQR) age was 79 (66-87) years and $58(27.2 \%)$ patients were male, and most two-thirds (141 [66.2\%]) were functionally independent (Table 1). The most frequent co-morbidities were hypertension (103,

This article is protected by copyright. All rights reserved. 
$48.4 \%)$, ischemic heart disease $(58,27.2 \%)$, heart failure $(45,21.1 \%)$, diabetes $(36,16.9 \%)$, chronic kidney disease $(27,12.7 \%)$, cerebro-vascular disease $(23,10.8 \%)$ and malignancy $(21$, 9.9\%).

Pre-operatively, 185 (86.9\%) patients had an electrocardiogram (ECG), of which 94 (44.1\%) were normal, 17 (8.0\%) revealed left bundle branch block; $13(6.1 \%)$ revealed right bundle branch block; 3 (1.4\%) had AV node block; 8 (3.8\%) had evidence of previous myocardial infarction; 17 (8.0\%) had other repolarization abnormalities and 41 (19.2\%) had some other abnormality.

Trans-thoracic echocardiography findings were documented in 53 (24.9\%) patients and left ventricular function was reported as normal, moderately depressed, and severely depressed in $36(68 \%), 14(26 \%)$, and $3(6 \%)$ of patients, respectively. Details of pre-operative vital signs and medication administration are shown in table 2. Pre-morbidly, 18 patients were on diuretics, and two were on GTN-patches.

\section{Details of surgery and anaesthesia}

Most surgeries were non-elective and most $(160,75.1 \%)$ patients received bolus vasopressor therapy for hypotension intra-operatively (Table 1). Vasopressors were more commonly given as a bolus than an infusion and were also administered in the recovery room in $19(8.9 \%)$ of patients. Details of anaesthesia are shown in table 2. Most patients received opioid analgesia after surgery, with 142 (66.7\%) receiving oral opioids, 28 (13.1\%) parenteral opioids and 161 (75.6) patient-controlled analgesia (PCA), in isolation or in combination with oral opioids. Intra-operative blood transfusion was relatively uncommon (12 [5.6\%]).

This article is protected by copyright. All rights reserved. 


\section{Details of the RRT activation and management}

Characteristics of the RRT activations are presented in table 1 and 3. Most RRT activations occurred in the first 24 hours after surgery, although 22 (10.3\%) occurred pre-operatively. There was a diurnal variation in RRT activations, with most occurring during working hours (Figure 1). Presumed hypovolemia, presumed infection, and arrhythmia were the most common suspected aetiology of hypotension documented in the electronic RRT database, and most RRT activations led to some additional investigation and treatment being performed (Table 3). Many patients had more than one precipitant for the RRT call (Table 1). During the RRT activation, median (IQR) creatinine was 80 (59-115) mmol/L, median haemoglobin was 94 $(82-107) \mathrm{g} / \mathrm{L}$ and median lactate was $1.7(1.3-2.3) \mathrm{mmol} / \mathrm{L}$.

The most common therapy was a fluid bolus, which was administered in $81.2 \%$ of cases (Table 4). Amongst the 173 patients that received fluid bolus during RRT call, information on the type of fluid was available in 162 cases (93.6\%). Of those 162 cases, 134 (82.7\%) received crystalloids (typically balanced salt solutions) and $28(17.3 \%)$ received albumin-based colloids.

Other treatments occurred in more than one-third of calls including blood transfusion and withholding of medications or ceasing patient-controlled analgesia. Only 3 patients had a cortisol measured around the time of the RRT call which were 405,562 , and $826 \mathrm{nmol} / \mathrm{L}$, all of which were above the lower limit of the laboratory reference range.

In only 21 (9.9\%) RRT activations no treatment was administered. Before the RRT activation 144 (67.1\%) of patients were for full treatment and, after the RRT activations a new limitation of medical treatment was introduced in $11(5.1 \%)$ patients.

This article is protected by copyright. All rights reserved. 


\section{Differences in characteristics and patient outcome according to fluid bolus administration}

Compared with the 40 patients who did not receive a fluid bolus during the RRT activation, the 173 patients who received a fluid bolus were less likely to be male, and more likely to have hypovolaemia as the presumed cause of the RRT call (Table 1$)$. Notably, $9 / 40$ (22.5\%) patients that did not get a fluid bolus were presumed to be hypovolemic (Table 1). However, only 9/163 (5.5\%) of patients with a presumptive diagnosis of hypovolemia did not appear to get a fluid bolus.

The time between RRT activation and surgery was clinically and statistically different according to whether the patient received a fluid bolus during the RRT call. Thus, the median (IQR) time between the RRT call and surgery was $10(4.0-26.5)$ hours for the 173 patients who received a fluid bolus during their first RRT call, compared with 33 (15.5-61.5) hours for the 40 patients who did not receive a fluid bolus ( $p<0.001$; Figure 2 ). Patients who received a fluid bolus were less likely to receive a vasoactive medication during the RRT call, and less likely to need ICU admission during that hospital stay (Table 1).

\section{Characteristics and patient outcome associated with intra-operative cement utilization}

When compared with the 154 patients who did not have intra-operative cement use, the 59 patients with intra-operative cement use were more likely to have hip and knee arthroplasty surgery. However, there were no other differences in patient characteristics, pre-operative medication use, presumed cause of the RRT call, treatments given during the RRT call, or inhospital patient outcomes (Table 6; appendix).

\section{Characteristics and patient outcome associated with renin-angiotensin axis blockers}


Sixty-eight (31.9\%) patients received ACEi and angiotensin 2 receptor blockers (A2RBs). Such patients were less likely to receive intra-operative vasopressor therapy, compared with those who did not. Otherwise, there were no differences in the characteristics and outcomes of such patients (Table 7; appendix).

\section{Outcomes of the cohort}

Hospital mortality was $8.5 \%$ (18 patients) in patients with RRT activation for hypotension. Of the patients discharged alive, 57 (26.8\%) were transferred to other facilities. Eleven (5.2\%) patients were transferred for ICU or HDU after the RRT activation, 29 (13.6\%) were admitted to ICU at some stage during the index hospital admission, and 73 (34.3\%) had more than one RRT activation (Table 4). There were $10 \mathrm{ICU}$ and $1 \mathrm{HDU}$ admissions immediately after the RRT call. Compared with those not admitted to critical care, patients were similar in relation to age $(p=0.622)$; gender distribution $(p=0.161)$, functional independence prior to admission ( $p=0.138)$, presence of LOMTs before the RRT $(p=0.287)$ and proportion of RRT calls due to presumed hypovolemia $(p=0.300)$. Mortality was $16 / 202(7.9 \%)$ in patients not admitted to ICU or HDU after RRT call versus $2 / 11(18.2 \%)$ in patients admitted to ICU or HDU after RRT call $(p=0.235)$. There were $22(10.4 \%)$ patients who had a RRT all pre-operatively. Compared with patients who had a post-operative RRT call, there were no differences in the proportion admitted to ICU ( $p=0.192)$ or in-hospital mortality (0.845).

There were 140 patients who had a single RRT call and 73 that had more than one call. Compared with patients who had a single call, those with repeat calls were less likely to be male (19.4\% vs $31.7 \% ; p=0.06)$, had an older median age ( $82(20-100)$ vs $78(51-97)$ years; $p=$ $0.004)$ and more likely to receive a fluid bolus during their first call $(90.4 \%$ vs $76.4 \% ; p=0.013)$.

This article is protected by copyright. All rights reserved. 


\section{Associations with in-hospital mortality}

Patients who died in hospital were older, more likely to be functionally dependent, and more likely to experience an arrhythmia or presumed infection during the RRT call. In addition, those who died in hospital received less perioperative fluid, were more likely to need urgent surgery, and were more likely to have limitations of medical treatment both before and after the RRT activation (Table 5). Patients who had repeat calls were more likely to die in hospital (13.7\% vs 5.7\%; $p=0.047)$. Administration of a fluid bolus during RRT review was not associated with a difference in the risk of mortality.

This article is protected by copyright. All rights reserved. 


\section{Discussion}

Summary of major findings

In this retrospective study of adult orthopaedic patients, we found that one-third of first RRT activations were due to hypotension. Such patients were elderly, with a high frequency of cardio-vascular and renal comorbidities and often needed urgent surgery. Pre-operative antihypertensive medication administration was common, as was the need for intra-operative vaso-active medications. Although fluid bolus therapy was commonly administered during RRT activation, one-third of patients required other treatments. Patients who received a fluid bolus during the RRT activation had a shorter time between the first call and surgery and appeared to be at lower risk of in-hospital death. Finally, $13.6 \%$ of patients were admitted to the ICU during hospitalization and an overall mortality was $8.5 \%$.

Comparison with previous studies

In our study of orthopaedic patients, hypotension was associated with 32\% of RRT activations. This percentage is similar to data in non-orthopaedic patients at $31 \%$ as described by Bergmeir et.al(12), but greater than described in other populations. For instance, Mullins et al have described that isolated hypotension was the trigger for only $9 \%$ of generic RRT activations(14). In other studies, hypotension was responsible for $29 \%(15), 24 \%(16)$ and $25 \%(17)$ of all RRT activations.

Hypotension as a reason for RRT activation has been associated with hospital mortality in published literature involving generic RRT activations $(16,18,19)$, with mortality risk reported between $5 \%$ to $35 \%(12,15,18)$. In our study hospital mortality of $8.5 \%$ possibly reflecting the

This article is protected by copyright. All rights reserved. 
fact that most cases were due to hypovolemia, which have been shown to be associated with a lower mortality(15). Moreover, we analysed only the first RRT activation, and recurrent deterioration after initial stabilization has been associated to increased mortality(19).

Hypotension in orthopaedic patients has been analysed in only a few studies with most studies focussing on intraoperative hypotension $(20,21)$. Smith et al (15) analysed 900 RRT activations, of which 79 (9\%) were for orthopaedic patients, for whom hypotension due to presumed hypovolemia was the most common activation trigger at $19 \%$ of RRT activations. However, this study did not provide detailed information on patient characteristics or outcomes. Similar to the study by Bergmeir and co-workers(2) we have found that most patients with hypotension received a fluid bolus. However, more than one-third received additional or alternative treatments.

Study strengths and limitations

Our study is the first to specifically evaluate the characteristics of RRT activations due to hypotension in a large cohort of orthopaedic patients. We have identified important information related to treatment received during such calls, and differences in the timing of calls due to presumed hypovolemia. However, this study has several limitations. It is a singlecentre, retrospective study and, as such, generalizability may be limited. Moreover, because our aim was to describe the occurrence and characteristics of hypotensive RRT in orthopaedic surgery patients, we did not include a control group. This may limit comparative interpretation of our data. Nevertheless, this exploratory study raises interesting hypotheses regarding perioperative volume therapy that may be tested in further studies. The diagnosis of hypovolemia was presumptive, and information on fluid balance, urine output and jugular

This article is protected by copyright. All rights reserved. 
venous pressure were unreliably recorded. However, accurate assessment of intra-vascular volume status is notoriously difficult, imperfect and not based on a single parameter. In our study, such assessment, was done by the RRT medical team leader using all clinical information available. In addition, 9/40 (22.5\%) of patients with presumed hypovolemia did not appear to get a fluid bolus. This finding may be due to either misclassification, or failure to document the fluid bolus. We did not document whether diuretics or GTN patches were withheld preoperatively or record the specifics of peri-operative vasopressors administered. However, vasopressor boluses are typically metaraminol or ephedrine, and infusions metaraminol or much less frequently noradrenaline. We did not evaluate the differences in patients who had pre-operative functional dependence or limitations of medical treatment, although such variables were associated with in-hospital mortality. Finally, we did not assess for the presence of afferent limb failure prior to the RRT call, which may have influenced patient outcomes.

\section{Implications for clinicians and researchers}

Our findings imply that, while hypovolemia appeared to be the most common cause of hypotension, other important interventions, including critical care admission are needed in these patients. Moreover, given that hypovolemia requiring fluid intervention was the most clinical profile of our patients, they also imply that a more liberal intraoperative and postoperative fluid administration strategy may be desirable and may apply to these patients as it does in patients undergoing major abdominal surgery. ${ }^{22}$ Only a small proportion of patients had evaluation of adrenal function around the time of hypotension. This may be a future area of investigation. Finally, the high use of vasoactive drugs during surgery, their

This article is protected by copyright. All rights reserved. 
cessation at the end of surgery and the frequency of early RRT activation for hypotension imply that it may be desirable continue such medications in the first 6 to 12 hours of postoperative period in patients treated with vasopressor drugs during surgery. Such interventions may be challenging to achieve in instances where the admission and surgery is emergent.

\section{Conclusions}

Hypotension is a common reason for RRT activation in orthopaedic patients. Vasopressor therapy during surgery and presumed hypovolemia appears to be a common in such patients. A more liberal approach to fluid therapy, withholding of pre-operative anti-hypertensive and prolongation of vasopressor therapy in the early post-operative period may prevent such RRT calls in orthopaedic patients. Our findings provide the rationale and justification for larger studies investigating perioperative strategies to minimize perioperative hypotension in patients undergoing orthopaedic surgery.

This article is protected by copyright. All rights reserved. 


\section{References}

1. Kurtz S, Ong K, Lau E, Mowat F, Halpern M. Projections of primary and revision hip and knee arthroplasty in the United States from 2005 to 2030. J Bone Joint Surg Am.

2007;89(4):780-5.

2. Liu J, Ahn J, Elkassabany NM. Optimizing perioperative care for patients with hip fracture. Anesthesiol Clin. 2014;32(4):823-39.

3. Taylor JM, Gropper MA. Critical care challenges in orthopedic surgery patients. Crit Care Med. 2006;34(9 Suppl):S191-9.

4. Memtsoudis SG, Sun X, Chiu YL, Nurok M, Stundner O, Pastores SM, et al. Utilization of critical care services among patients undergoing total hip and knee arthroplasty: epidemiology and risk factors. Anesthesiology. 2012;117(1):107-16.

5. Jones DA, DeVita MA, Bellomo R. Rapid-response teams. N Engl J Med. 2011;365(2):139-46.

6. Tee A, Calzavacca P, Licari E, Goldsmith D, Bellomo R. Bench-to-bedside review: The MET syndrome--the challenges of researching and adopting medical emergency teams. Crit Care. 2008;12(1):205.

7. Chen J, Ou L, Hillman KM, Flabouris A, Bellomo R, Hollis SJ, et al. Cardiopulmonary arrest and mortality trends, and their association with rapid response system expansion. Med J Aust. 2014;201(3):167-70.

8. Jones D, Bellomo R, DeVita MA. Effectiveness of the Medical Emergency Team: the importance of dose. Crit Care. 2009;13(5):313.

9. Jung B, Daurat A, De Jong A, Chanques G, Mahul M, Monnin M, et al. Rapid response team and hospital mortality in hospitalized patients. Intensive Care Med. 2016;42(4):494-504.

10. . !!! INVALID CITATION !!! 7.

11. Kilci O, Un C, Sacan O, Gamli M, Baskan S, Baydar M, et al. Postoperative Mortality after Hip Fracture Surgery: A 3 Years Follow Up. PLoS One. 2016;11(10):e0162097.

12. Bergmeir C, Bilgrami I, Bain C, Webb GI, Orosz J, Pilcher D. Designing a more efficient, effective and safe Medical Emergency Team (MET) service using data analysis. PLoS One. 2017;12(12):e0188688.

13. Donaldson AJ, Thomson HE, Harper NJ, Kenny NW. Bone cement implantation syndrome. Br J Anaesth. 2009;102(1):12-22.

14. Mullins C, Psirides A. Activities of a Medical Emergency Team: a prospective observational study of 795 calls. Anaesth Intensive Care. 2016;44(1):34-43.

15. Smith RJ, Santamaria JD, Faraone EE, Holmes JA, Reid DA. Rapid response team diagnoses: frequencies and related hospital mortality. Crit Care Resusc. 2017;19(1):71-80.

16. Boniatti MM, Azzolini N, da Fonseca DL, Ribeiro BS, de Oliveira VM, Castilho RK, et al. Prognostic value of the calling criteria in patients receiving a medical emergency team review. Resuscitation. 2010;81(6):667-70.

17. Barwise A, Thongprayoon C, Gajic O, Jensen J, Herasevich V, Pickering BW. Delayed Rapid Response Team Activation Is Associated With Increased Hospital Mortality, Morbidity, and Length of Stay in a Tertiary Care Institution. Crit Care Med. 2016;44(1):54-63.

This article is protected by copyright. All rights reserved. 
18. Quach JL, Downey AW, Haase M, Haase-Fielitz A, Jones D, Bellomo R. Characteristics and outcomes of patients receiving a medical emergency team review for respiratory distress or hypotension. J Crit Care. 2008;23(3):325-31.

19. Khalid I, Qabajah MR, Hamad WJ, Khalid TJ, Digiovine B. Outcome of hypotensive ward patients who re-deteriorate after initial stabilization by the Medical Emergency Team. J Crit Care. 2014;29(1):54-9.

20. Zainudheen A, Scott IA, Caney X. Association of renin angiotensin antagonists with adverse perioperative events in patients undergoing elective orthopaedic surgery: a casecontrol study. Intern Med J. 2017;47(9):999-1005.

21. Calloway JJ, Memtsoudis SG, Krauser DG, Ma Y, Russell LA, Goodman SM.

Hemodynamic effects of angiotensin inhibitors in elderly hypertensives undergoing total knee arthroplasty under regional anesthesia. J Am Soc Hypertens. 2014;8(9):644-51.

This article is protected by copyright. All rights reserved. 


\section{Figure legends and tables}

Figure 1: Bar graph showing diurnal variation of RRT activation over $24 \mathrm{hr}$ period.

Figure 2: Box-whisker plot showing median (IQR) time intervals between surgery and RRT activation for patients who received a fluid bolus during the activation, compared with those who did not.

Table 1: Patient demographics, surgical approach, and RRT features according to fluid bolus administration during RRT activation for hypotension.

Table 2. Characteristics of the pre-operative vital signs and anaesthesia for patients receiving RRT activation for hypotension

Table 3. Details of vital signs, investigations and management during RRT activation for hypotension

Table 4. Outcomes of the 213 patients experiencing RRT activation due to hypotension

Table 5: Differences in characteristics according to survival status amongst RRT activations due to hypotension

\section{Acknowledgment}

We wish to acknowledge Ms Nada Marhoon for providing information related to cortisol levels.

This article is protected by copyright. All rights reserved. 
Table 1: Patient demographics, surgical approach, and RRT features according to fluid bolus administration during RRT activation for hypotension.

\begin{tabular}{|c|c|c|c|c|}
\hline Characteristic & $\begin{array}{l}\text { Overall cohort ( } \mathrm{N} \\
=213 \text { ) }\end{array}$ & $\begin{array}{l}\text { No fluid bolus } \\
(\mathrm{N}=40)\end{array}$ & $\begin{array}{l}\text { Fluid bolus } \\
(\mathrm{N}=173)\end{array}$ & p \\
\hline Age, median (IQR) & $79(66-87)$ & $81(72-87)$ & $79(65-87)$ & 0.36 \\
\hline Male sex, N (\%) & $58(27.2)$ & $17(42.5)$ & $41(23.7)$ & 0.024 \\
\hline Performance status, N (\%) & & & & 0.076 \\
\hline Independent & $141(66.2)$ & $30(75)$ & $111(64.2)$ & \\
\hline Partially dependent & $36(16.9)$ & $5(12.5)$ & $31(17.9)$ & \\
\hline Full dependent & $17(8.0)$ & $0(0)$ & $17(9.8)$ & \\
\hline Missing data & $19(8.9)$ & $5(12.5)$ & $14(8.1)$ & \\
\hline Urgent surgery, $\mathrm{N}(\%)$ & $145(68)$ & $30(75)$ & $115(66.5)$ & 0.297 \\
\hline Type of surgery, $\mathrm{N}(\%)$ & & & & 0.768 \\
\hline Laminectomy & $22(10.3)$ & $6(15)$ & $16(9.2)$ & \\
\hline Femoral fracture & $23(10.8)$ & $3(7.5)$ & $20(11.6)$ & \\
\hline Hemi-arthroplasty of the hip & $27(12.7)$ & $4(10)$ & $23(13.3)$ & \\
\hline Hip fracture & $50(23.5)$ & $9(22.5)$ & $41(23.7)$ & \\
\hline Total hip replacement & $30(14.1)$ & $8(20)$ & $22(12.7)$ & \\
\hline Total knee replacement & $26(12.2)$ & $4(10)$ & $22(12.7)$ & \\
\hline Others & $35(16.4)$ & $6(15)$ & $29(16.8)$ & \\
\hline Cemented surgery, $\mathrm{N}(\%)$ & $59(27.7)$ & $10(25)$ & $49(28.3)$ & 0.672 \\
\hline Received pre-operative fluids & $110(51.6)$ & $21(52.5)$ & 89 (51.4) & 0.904 \\
\hline Preoperative fluids (ml), median (IQR) & $2000(1000-2000)$ & $2000(1000-2300)$ & $2000(1000-2000)$ & 0.931 \\
\hline Intraoperative fluids (ml), median (IQR) & $1000(1000-2000)$ & $1250(1000-2625)$ & $1000(1000-2000)$ & 0.332 \\
\hline Peri-operative fluid volume & $2000(1400-3000)$ & $3000(1000-3000)$ & $2000(1500-3000)$ & 0.54 \\
\hline Vasopressor bolus medication during surgery, $\mathrm{N}(\%)$ & $160(75.1)$ & $31(77.5)$ & $129(74.6)$ & 0.699 \\
\hline Vasoactive infusion during surgery, $\mathrm{N}(\%)$ & $33(15.5)$ & $10(25)$ & $23(13.3)$ & 0.065 \\
\hline Received fluids in recovery room, $\mathrm{N}(\%)$ & $26(12.2)$ & $5(12.5)$ & $21(12.1)$ & 0.95 \\
\hline Vasoactive medications in recovery room, $\mathrm{N}(\%)$ & $19(8.9)$ & $7(17.5)$ & $12(6.9)$ & 0.058 \\
\hline Days from admission to surgery, median (IQR) & $0(0-2)$ & $1(0-3)$ & $0(0-1)$ & 0.004 \\
\hline RRT activation before surgery, $\mathrm{N}(\%)$ & $22(10.3)$ & $7(17.5)$ & $15(8.7)$ & 0.101 \\
\hline $\begin{array}{l}\text { Hours from surgery to RRT activation, } \\
\text { median (IQR) }\end{array}$ & $14.5(4.0-31.2)$ & $33(15.5-61.5)$ & $10(4.0-26.5)$ & $<0.001$ \\
\hline \multicolumn{5}{|l|}{ Presumed cause of RRT activation, $\mathrm{N}(\%)$} \\
\hline Arrhythmias & $13(6.1)$ & $4(10)$ & $9(5.2)$ & 0.253 \\
\hline Infection suspected & $23(10.8)$ & $6(15)$ & $17(9.8)$ & 0.342 \\
\hline Bleeding & $3(1.4)$ & $0(0)$ & $3(1.7)$ & 0.402 \\
\hline Pulmonary embolism & $4(1.9)$ & $0(0)$ & $4(2.3)$ & 0.332 \\
\hline Anaphylaxis & $1(0.5)$ & $0(0)$ & $1(0.6)$ & 0.63 \\
\hline Autonomic dysfunction & $3(1.4)$ & $1(2.5)$ & $2(1.2)$ & 0.516 \\
\hline Presumed hypovolemia & $163(76.5)$ & $9(22.5)$ & $154(89)$ & $<0.001$ \\
\hline Benign hypotension & $23(10.8)$ & $19(47.5)$ & $4(2.3)$ & $<0.001$ \\
\hline
\end{tabular}




\section{Drugs}

Acute coronary syndrome

Other

Vasoactive drugs at RRT activation, N (\%)

Blood transfusion, $\mathrm{N}$ (\%)

ICU or HDU transfer after RRT activation, N (\%)

Any ICU admission during hospital stay, N (\%)

Full care before RRT activation, N (\%)

Full care after RRT activation, N (\%)

Hospital mortality, N (\%)
23 (10.8)

3 (1.4)

5 (2.3)

9 (4.2)

$30(14.1)$

$11(5.2)$

29 (13.6)

143 (67.1)

$133(62.4)$

18 (8.5)
3 (7.5)

0 (0)

3 (7.5)

3 (7.5)

6 (15)

2 (5)

13 (32.5)

26 (65)

26 (65)

4 (10)
20 (11.6)

3 (1.7)

2 (1.2)

6 (3.5)

24 (13.9)

9 (5.2)

16 (9.2)

$117(67.6)$

107 (61.8)

14 (8.1)
0.456

0.402

0.017

0.253

0.853

0.958

$<0.001$

0.75

0.868

0.696

$\mathrm{ml}=$ millilitres; IQR = inter-quartile range; ICU = intensive care unit; HDU = high dependency unit; RRT = rapid

response team;

This article is protected by copyright. All rights reserved. 
Table 2. Characteristics of the pre-operative vital signs and anaesthesia for patients receiving RRT activation for hypotension

\begin{tabular}{ll}
\hline Characteristics & \\
\hline Vital signs and fluid therapy & $123(110-140)$ \\
Preoperative SBP, median (IQR) mmHg & $70(60-78)$ \\
Preoperative DBP, median (IQR) mmHg & $78(70-86)$ \\
Preoperative HR, median (IQR) & $12(9-16)$ \\
Preoperative fasting (hours), median (IQR) & $110(51.6)$ \\
Preoperative fluids, N (\%) & $504(504-2000)$ \\
Preoperative fluids (ml), median (IQR) & \\
\hline Medications given on morning of surgery N (\%) & \\
Angiotensin converting enzyme inhibitors (AECi) & $28(13.1)$ \\
Angiotensin 2 receptor blockers (A2RB) & $42(19.7)$ \\
Beta-blockers & $50(23.5)$ \\
\hline Type of anaesthesia, N (\%) & \\
$\quad$ General anaesthesia & $159(74.6)$ \\
$\quad$ Spinal anaesthesia & $53(24.9)$ \\
$\quad$ Epidural anaesthesia & $2(0.9)$ \\
$\quad$ Regional anaesthesia & $56(26.3)$ \\
\hline ASA status, median (IQR) & $3(3-3)$ \\
Surgery duration (minutes), median (IQR) & $90(55-149)$ \\
Intraoperative fluids (ml), median (IQR) & $1000(1000-2000)$ \\
\hline RBC transfusion during surgery, N (\%) & $12(5.6)$ \\
Cardiac arrest during surgery, N (\%) & $1(0.5)$ \\
Unplanned ICU admission after surgery, N (\%) & $9(4.2)$ \\
\hline
\end{tabular}

$\mathrm{SBP}=$ Systolic blood pressure; $\mathrm{DBP}=$ diastolic blood pressure; $\mathrm{HR}=$ heart rate; $\mathrm{ml}=$ millilitres; $\mathrm{RBC}=$ red blood cell; ICU = intensive care unit.

This article is protected by copyright. All rights reserved. 
Table 3. Details of vital signs, investigations and management during RRT activation for hypotension

\begin{tabular}{ll}
\hline Characteristics & \\
\hline Vital signs at RRT activation & $2(0-5)$ \\
Pain score ${ }^{*}$, median (IQR) & $80(77-85)$ \\
SBP, median (IQR) mmHg & $50(45-55)$ \\
DBP, median (IQR) mmHg & $80(68-92)$ \\
HR, median (IQR) & $17(16-20)$ \\
Respiratory rate, median (IQR) & $36(16.9)$ \\
Altered mental status, & \\
\hline Resources utilized, N (\%) & $136(63.8)$ \\
Blood tests performed & $40(18.8)$ \\
Chest X-Ray performed & $161(75.6)$ \\
ECG performed & $6(2.8)$ \\
Echo performed & $6(2.8)$ \\
CT scan performed & $4(1.9)$ \\
Consultation with other medical specialties & \\
\hline Treatments performed, N (\%) & $173(81.2)$ \\
Fluids administered & $10(4.7)$ \\
Antibiotics & $30(14.1)$ \\
RBC transfusion & $26(12.2)$ \\
Withhold medications & $14(6.6)$ \\
Withhold patient controlled analgesia & $9(4.2)$ \\
Vasoactive drugs & $21(9.9)$ \\
No treatment performed & $400(250-500)$ \\
\hline Volume fluid bolus (ml), median (IQR) & \\
\hline SBP = Systolic blood pressure; DBP = diastolic blood pressure; HR $=$ heart rate; ml = millilitres; RBC = red \\
blood cell; CT = computerised tomography; ECG = electro-cardiogram. * Pain scores measured by a \\
numerical rating scale from 0 (no pain) to 10 (worst pain imaginable).
\end{tabular}

This article is protected by copyright. All rights reserved. 
Table 4. Outcomes of the 213 patients experiencing RRT activation due to hypotension

\begin{tabular}{ll}
\hline Characteristics & \\
\hline Immediate RRT outcome N (\%) & $10(4.7)$ \\
Transferred to ICU & $1(0.5)$ \\
Transferred to HDU & $2(0.9)$ \\
Death on the ward & $11(5.1)$ \\
Patients with new LOMT & $29(13.6)$ \\
Any ICU admission & \\
\hline Subsequent outcomes & $73(34.3)$ \\
More than one RRT activation, N (\%) & $13(0-34.5)$ \\
Length of stay in the ICU (hours), median (IQR) & $21(6-38)$ \\
Length of stay in the hospital (days), median (IQR) & \\
Hospital outcome, N (\%) & $18(8.5)$ \\
Dead & $137(64.3)$ \\
Discharged home & $45(21.1)$ \\
Nursing home & $12(5.7)$ \\
Hospital transfer & $1(0.5)$ \\
Other &
\end{tabular}

$\mathrm{ICU}=$ Intensive care unit; $\mathrm{HDU}=$ high dependency unit; $\mathrm{LOMT}=$ limitations of medical treatment; RRT = Rapid Response Team; IQR = inter-quartile range.

This article is protected by copyright. All rights reserved. 
Table 5: Differences in characteristics according to survival status amongst RRT activations due to hypotension

\begin{tabular}{|c|c|c|c|}
\hline Characteristic & $\begin{array}{l}\text { Survived hospital } \\
\text { ( } \mathrm{N}=195)\end{array}$ & $\begin{array}{l}\text { Died in hospital } \\
(\mathrm{N}=18)\end{array}$ & p-value \\
\hline Age, median (IQR) & $78(65-86)$ & $89(82-91)$ & $<0.001$ \\
\hline \multicolumn{4}{|l|}{ Performance status, $\mathrm{N}(\%)$} \\
\hline Independent & $133(75.1)$ & $8(47.1)$ & \multirow{4}{*}{0.004} \\
\hline Partially dependent & $32(18.1)$ & $4(23.5)$ & \\
\hline Full dependent & $12(6.8)$ & $5(29.4)$ & \\
\hline Missing data & $18(9.2)$ & $1(5.6)$ & \\
\hline Urgent surgery, $\mathrm{N}(\%)$ & $128(65.6)$ & $17(94.4)$ & 0.012 \\
\hline \multicolumn{4}{|l|}{ Type of surgery, $\mathrm{N}(\%)$} \\
\hline Laminectomy & $21(10.8)$ & $1(5.6)$ & \multirow{7}{*}{0.134} \\
\hline Femoral fracture & $21(10.8)$ & $2(11.1)$ & \\
\hline Hemi-arthroplasty of the hip & $25(12.8)$ & $2(11.1)$ & \\
\hline Hip fracture & $41(21.0)$ & $9(50.0)$ & \\
\hline Total hip replacement & $29(14.9)$ & $1(5.6)$ & \\
\hline Total knee replacement & $26(13.3)$ & $0(0)$ & \\
\hline Others & $32(16.4)$ & $3(16.7)$ & \\
\hline \multicolumn{4}{|l|}{ Presumed cause of RRT activation, $\mathrm{N}(\%)$} \\
\hline Arrhythmias & $8(4.1)$ & $5(27.8)$ & $<0.001$ \\
\hline Infection suspected & $17(8.7)$ & $6(33.3)$ & 0.001 \\
\hline Bleeding & $3(1.5)$ & $0(0)$ & 0.596 \\
\hline Pulmonary embolism & $3(1.5)$ & $1(5.6)$ & 0.23 \\
\hline Anaphylaxis & $1(0.5)$ & $0(0)$ & 0.761 \\
\hline Autonomic dysfunction & $2(1.0)$ & $1(5.6)$ & 0.119 \\
\hline Presumed hypovolemia & $148(75.9)$ & $15(83.3)$ & 0.476 \\
\hline Benign hypotension & $22(11.3)$ & $1(5.6)$ & 0.454 \\
\hline Drugs & $23(11.8)$ & $0(0)$ & 0.123 \\
\hline Acute coronary syndrome & $2(1.0)$ & $1(5.6)$ & 0.119 \\
\hline Other & $4(2.1)$ & $1(5.6)$ & 0.347 \\
\hline Perioperative fluids (ml), median (IQR) & $1000(1000-2000)$ & $1000(1000-1000)$ & 0.012 \\
\hline Vasopressor treatment during surgery, $\mathrm{N}(\%)$ & $147(75.4)$ & $13(72.2)$ & 0.767 \\
\hline Vasoactive infusion, $\mathrm{N}(\%)$ & $31(15.9)$ & $2(11.1)$ & 0.591 \\
\hline Fluids administered at RRT activation, $\mathrm{N}(\%)$ & $159(81.5)$ & $14(77.8)$ & 0.696 \\
\hline $\begin{array}{l}\text { Volume fluid bolus (ml) at RRT activation, } \\
\text { median (IQR) }\end{array}$ & $500(250-500)$ & $250(250-625)$ & 0.633 \\
\hline Vasoactive drugs at RRT activation, $\mathrm{N}(\%)$ & $8(4.1)$ & $1(5.6)$ & 0.769 \\
\hline $\begin{array}{l}\text { Transferred to ICU or HDU after RRT } \\
\text { activation, } \mathrm{N}(\%)\end{array}$ & $9(4.6)$ & $2(11.1)$ & 0.233 \\
\hline
\end{tabular}

This article is protected by copyright. All rights reserved. 


\begin{tabular}{l|l|l|l}
\hline Repeated RRT call, N (\%) & $63(32.3)$ & $10(55.6)$ & 0.047 \\
\hline Any ICU admission during hospital stay, N (\%) & $24(12.3)$ & $5(27.8)$ & 0.067 \\
\hline Full care before RRT activation, N (\%) & $137(70.3)$ & $6(33.3)$ & 0.001 \\
\hline Full care after RRT activation, N (\%) & $129(66.2)$ & $4(22.2)$ & 0.001 \\
\hline
\end{tabular}

$\mathrm{RRT}=$ Rapid response team; ICU = intensive care unit; IQR = inter-quartile range; $\mathrm{ml}$ = millilitres

This article is protected by copyright. All rights reserved. 


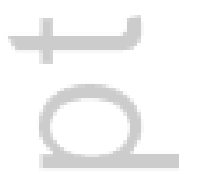

This article is protected by copyright. All rights reserved. 


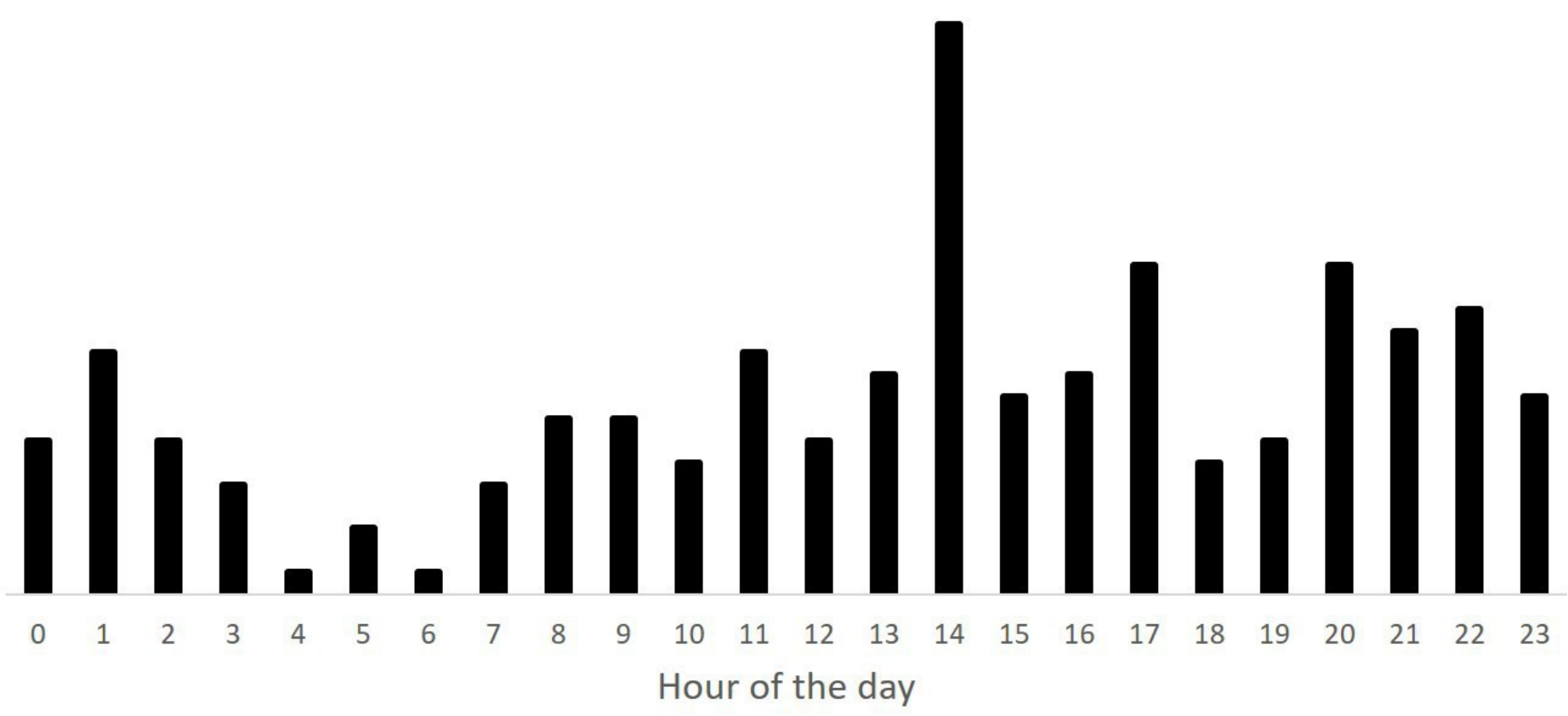

IMJ_14374_Figure 1.jpg 


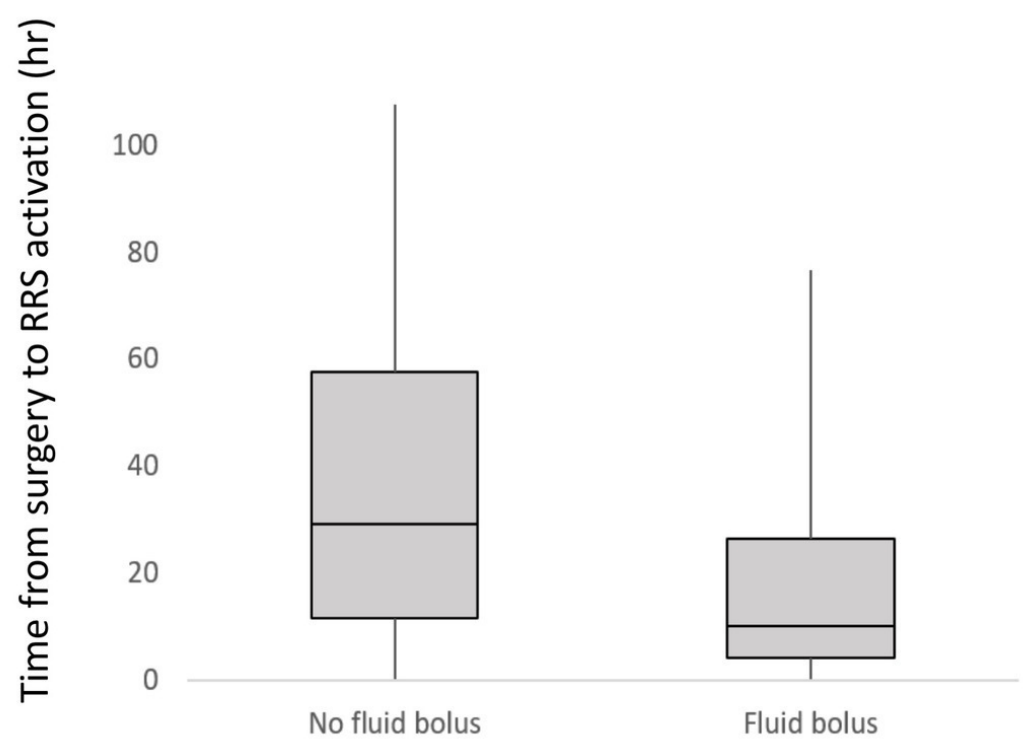

IMJ_14374_Figure 2.jpg

This article is protected by copyright. All rights reserved. 


\section{University Library}

\section{- M M N E R VA A gateway to Melbourne's research publications}

Minerva Access is the Institutional Repository of The University of Melbourne

\section{Author/s:}

Ramos, JGR;Zhang, R;Maher, B;Hardidge, A;Weinberg, L;Robbins, R;Peyton, PJ;Bellomo, R;Jones, D

Title:

Characteristics and outcomes of rapid response team activations for hypotension in orthopaedic patients

Date:

2020-01-01

Citation:

Ramos, J. G. R., Zhang, R., Maher, B., Hardidge, A., Weinberg, L., Robbins, R., Peyton, P. J., Bellomo, R. \& Jones, D. (2020). Characteristics and outcomes of rapid response team activations for hypotension in orthopaedic patients. INTERNAL MEDICINE JOURNAL, 50 (1), pp.61-69. https://doi.org/10.1111/imj.14374.

Persistent Link:

http://hdl.handle.net/11343/275225 